\title{
Certain personal and environmental factors as predictors of thermal sensation perceived by a population of students in a university setting from Timisoara, Romania: a case study
}

Cristina I. Petrescu $\mathrm{u}^{1,2}$

\begin{abstract}
Background: The aim of the performed study was to investigate personal and environmental factors as predictors of thermal sensation perceived by a population of students in a university setting.

Methods: The study consisted of two samples, a winter sample (154 students: 44.2\% males and 55.8\% females, aged 19-30 years) and a spring sample (147 students: $52.4 \%$ males and $47.6 \%$ females, aged 19-30 years), randomly selected from the same population of students. The method was an observational inquiry (case study) with a standardized questionnaire (11 items, 3 items for thermal sensation assessing through 3 scales with 3, 5 and 7 steps, alpha Cronbach's index 0.854) applied and establishing 3 microclimate factors (air temperature, relative humidity and wind velocity), with calculation of normal effective temperature. The survey was performed over four successive days, during two seasons (winter-February and spring-May).

Results: The performed study demonstrated a tendency of students to perceive the comfortably cold more frequently than comfortably warm throughout the 4 days of the survey during the winter, except Monday. Thermal sensation of discomfort was more frequently perceived as warm than cold throughout the spring time of the survey and winter, except Tuesday. Predictors of thermal sensation perceived by students in the amphitheatre were as follows: nationality $(-2$ loglikelihood change or chi square $=42.12$, Sig. 0.000), relative humidity (chi square $=10.65$, Sig. 0.005$)$ and gender during the winter, and wind velocity (change in -2 loglikelihood =11.96, Sig. 0.001) and nationality during the spring.
\end{abstract}

Conclusions: Certain personal and environmental factors were suggested as predictors for thermal sensation perceived by a population of students in a study setting.

Keywords: Thermal sensation, Students, University, Personal and environmental factors, Case study

\section{Background}

Environmental and individual factors interact and determine a great variation of thermal sensation perception. Recent research performed in the area indicated how environmental factors intervene in heat exchange between whole body [1] and environment through physiological equivalent temperature (PET) [2], predicted mean vote

Correspondence: cpetrescu64a@yahoo.com; petrescu.cristina@umft.ro ${ }^{1}$ Department of Hygiene, "Victor Babes" University of Medicine and Pharmacy Timisoara, Victor Babes 16, 300226 Timisoara, Romania

${ }^{2}$ Sabinei 3A/18, 300424 Timisoara, Romania
(PMV) [3], actual sensation vote (ASV) and Universal Thermal Climate Index (UTCI) $[4,5]$ estimation of thermal sensation in investigated people. Normal effective temperature (NET) calculation was improved by $\mathrm{Li}$ and Chen, in $2000[5,6]$.

A gap of knowledge is registered in eastern European countries regarding microclimate factors related to thermal sensation perceived in study settings with classical architecture combined with modern means (PVC windows) to save energy. Climate changes worsen the existent situation through the great variation of 
meteorological conditions and through exhaustion of man's mechanisms of adaptation. Assessment of the thermal sensation perceived by students in a study setting and of the factors (environmental and personal) which could modify it, offers the possibility to improve microclimate conditions and to assure thermal comfort of the students. The aim of the conducted study was to investigate personal and environmental factors as predictors of thermal sensation perceived by a population of students in a university setting, classically built and naturally ventilated, from Timisoara, in two seasons, winter and spring.

\section{Methods}

The study was performed on two different samples of Romanian and English language students selected through random sampling: a winter sample of 154 students (44.2\% males and $55.8 \%$ females, aged $19-30$ years) and a spring sample of 147 students $(52.4 \%$ males and $47.6 \%$ females, aged $19-30$ years) from the same population of students (second year of study). The informed consent of each student to participate in the study was asked for and obtained.

The study setting was an amphitheatre $\left(140-\mathrm{m}^{2}\right.$ plane surface, 14-m length and 10-m width, 6-m height, 143 places on inclined surface) of the University with thick walls from bricks and PVC windows (5 on each lateral side and 4 on the posterior side). It is a naturally ventilated (NV) building: [6]. The central heating system consists in radiators placed on both lateral sides ( 3 on each side) and on the posterior side ( 2 radiators) of the amphitheatre, used during the winter. There is not a cooling system during the spring or summer.

The method was an observational inquiry (case study) and consisted of a standardized questionnaire applied and in an assessment of air temperature, relative humidity and wind velocity in the amphitheatre. The questionnaire consisted of 11 items referring to thermal sensation perception, gender, age, nationality, presence of illness, of tiredness and of stress, sensitivity to cold, and sensitivity to hot, clothes worn during the lecture, effects of comfortable thermal sensation perception on performance and wellbeing. The questionnaire was applied on four successive days in a week (Monday-M, Tuesday-Tu, Wednesday-W, Thursday-Th), at the end of February (during the winter) and at the middle of May (during the spring), at the beginning of the lectures. The questionnaire was completed anonymously over a period of $10 \mathrm{~min}$. Measurement of the microclimate factors, air temperature, relative humidity and wind velocity was done with the aid of a base station component (with a sensor for indoor air temperature and air relative humidity measurement) of a weather station Oregon WMR200 and an air velocity meter 9515. The measurement was done during and after completing the questionnaire ( $30 \mathrm{~min}$, maximum 25 points), on the lateral side and in the middle of each row with six places (second, third, fourth, fifth and sixth rows doubly placed with a central space between them in the amphitheatre) in which students usually sat. The positioning of students who completed the questionnaire was carefully monitored and related to the measurement values of microclimate factors. The number of places of microclimate factor measurement differed depending on the number of students who completed the questionnaire on each day of assessment.

Normal effective temperature (NET) was calculated by the aid of formula [5]:

$$
\begin{aligned}
\mathrm{NET}=37-\frac{37-T}{0.68-0.0014 \times \mathrm{RH}+\frac{1}{1.76+1.4 \times \nu^{0.75}}} \\
-0.29 \times T \times(1-0.01 \times \mathrm{RH})
\end{aligned}
$$

where NET is the normal effective temperature (degree effective temperature, ${ }^{\circ} \mathrm{ET}$ ), $T$ is the air temperature (degree Celsius, $\left.{ }^{\circ} \mathrm{C}\right), \mathrm{RH}$ is the relative humidity (\%) and $v$ is the wind velocity (metre/second, $\mathrm{m} / \mathrm{s}$ ).

Thermal sensation perceived by the surveyed students was assessed using 3 scales (with 3 steps-warm, pleasant, cold; 5 steps-uncomfortably warm, comfortably warm, pleasant, comfortably cold, uncomfortably cold; and 7 steps-very warm, warm, slightly warm, pleasant, slightly cold, cold and very cold) $[3,7]$. Reliability of the items regarding perceived thermal sensation (3-, 5- and 7-step scales) was high-alpha Cronbach's index 0.845.

Statistical analysis (chi square, Spearman correlations, Kruskal-Wallis $H$, Mann-Whitney $U$ with Bonferroni correction, multinomial and binary logistic regression) was performed by the aid of SPSS 20 program. In the performed study, personal or environmental factors assessed were related to the perceived thermal sensation (scale with 3 steps) through multinomial logistic regression (during the winter-outcome variable with 3 categories: warm, pleasant and cold) and binary logistic regression (during the spring-outcome variable with 2 categories: warm and no-warm or pleasant; cold category with 1 case was excluded).

\section{Results}

\section{Personal factors}

Personal factor results for gender, age, and body mass index (BMI), nationality, illness state, tiredness, stress, sensitivity to cold and to hot environment, and clothes are presented in Table 1 . Effects of the comfortable thermal sensation perceived by students on performance and wellbeing are also revealed in Table 1. 
Table 1 Personal factors and effects of comfortable perceived thermal sensation during the winter and spring surveys

\begin{tabular}{|c|c|c|c|c|c|}
\hline \multicolumn{2}{|l|}{ Personal factors } & \multirow{2}{*}{$\begin{array}{l}\text { Winter (number) } \\
68\end{array}$} & \multirow{2}{*}{$\begin{array}{l}\text { Winter (\%) } \\
44.16\end{array}$} & \multirow{2}{*}{$\begin{array}{l}\text { Spring (number) } \\
77\end{array}$} & \multirow{2}{*}{$\begin{array}{l}\text { Spring (\%) } \\
52.38\end{array}$} \\
\hline Gender & Male & & & & \\
\hline & Female & 86 & 55.84 & 70 & 47.62 \\
\hline Age & $19-30$ years & 154 & 100 & 147 & 100 \\
\hline \multirow[t]{3}{*}{ BMI } & $<18.5$ & 8 & 5.20 & 11 & 7.48 \\
\hline & $18.5-25$ & 121 & 78.57 & 110 & 74.83 \\
\hline & $>25$ & 25 & 16.23 & 26 & 17.69 \\
\hline \multirow[t]{8}{*}{ Nationality } & Romanian & 54 & 35.06 & 46 & 31.29 \\
\hline & Israeli & 27 & 17.53 & 28 & 19.05 \\
\hline & German & 18 & 11.69 & 19 & 12.93 \\
\hline & Italian & 20 & 12.99 & 14 & 9.52 \\
\hline & Greek & 5 & 3.24 & 6 & 4.08 \\
\hline & Syrian & 4 & 2.60 & 3 & 2.04 \\
\hline & Indian & 4 & 2.60 & 4 & 2.72 \\
\hline & Other & 22 & 14.29 & 27 & 18.37 \\
\hline \multirow[t]{2}{*}{ Illness state } & Presence & 19 & 12.33 & 11 & 7.48 \\
\hline & Absence & 135 & 87.67 & 136 & 92.52 \\
\hline \multirow[t]{2}{*}{ Tiredness } & Presence & 75 & 48.70 & 69 & 46.94 \\
\hline & Absence & 79 & 51.30 & 78 & 53.06 \\
\hline \multirow[t]{3}{*}{ Stress } & Presence & 42 & 27.27 & 85 & 57.82 \\
\hline & Absence & 112 & 72.73 & 62 & 42.18 \\
\hline & Extremely sensitive & 8 & 5.19 & 10 & 6.80 \\
\hline \multirow[t]{4}{*}{ Sensitivity to cold } & Very sensitive & 42 & 27.27 & 33 & 22.45 \\
\hline & Moderate sensitive & 82 & 53.25 & 80 & 54.42 \\
\hline & Slightly sensitive & 22 & 14.29 & 24 & 16.33 \\
\hline & Extremely sensitive & 11 & 7.14 & 11 & 7.48 \\
\hline \multirow[t]{3}{*}{ Sensitivity to hot } & Very sensitive & 38 & 24.68 & 39 & 26.53 \\
\hline & Moderate sensitive & 70 & 45.45 & 76 & 51.70 \\
\hline & Slightly sensitive & 35 & 22.73 & 21 & 14.29 \\
\hline \multirow[t]{6}{*}{ Clothes } & T-shirts & 68 & 44.15 & 83 & 56.46 \\
\hline & Laboratory coats & 21 & 13.64 & 22 & 14.97 \\
\hline & Jackets & 20 & 12.99 & 12 & 8.16 \\
\hline & Other clothes & 28 & 18.18 & 26 & 17.69 \\
\hline & Bonnet & 2 & 1.30 & 2 & 1.36 \\
\hline & Scarf & 15 & 9.74 & 2 & 1.36 \\
\hline \multicolumn{6}{|c|}{ Effects of comfortable thermal sensation } \\
\hline Attention & Concentrate better & 52 & 33.77 & 72 & 48.98 \\
\hline Feeling & Well & 49 & 31.81 & 44 & 29.93 \\
\hline Physically & Relaxed & 44 & 28.57 & 21 & 14.29 \\
\hline Understanding & Understand better & 7 & 4.55 & 10 & 6.80 \\
\hline Other & Other & 2 & 1.30 & 0 & 0 \\
\hline
\end{tabular}

\section{Environmental factors}

The evolution of the air temperature, air humidity and wind velocity was complex, with variation through the same week. During the winter all investigated environmental factors had similar evolution: a decrease Monday-Tuesday and an increase Wednesday-Thursday. A similar evolution was found during the spring for relative humidity and wind 
velocity. Air temperature increased from Monday to Thursday, during the spring. Normal effective temperature (NET) presented a similar evolution with air temperature throughout the 4 days of investigation, during the winter and spring (Table 2). There was no significant space variation of the three microclimate factors around the median values at the time of measurement.

\section{Perceived thermal sensation in the amphitheatre}

The perceived thermal sensation assessed by the aid of the three scales (with 3, 5 and 7 steps), 4 days successively, during the winter and during the spring is revealed in Table 3.

The 3 different scales used to measure the perceived thermal sensation correlated between them and offered valuable information about the perceived comfortable thermal sensation and discomfort. Spearman correlation coefficients between the 3 applied scales were as follows: 0.823 (3-5 steps); 0.837 (3-7 steps) and 0.911 (5-7 steps), Sig. 0.000

\section{Comfortable thermal sensation and discomfort perceived during the winter and spring}

Comfortable thermal sensation was perceived as pleasant (scale with 3 steps), comfortably warm, pleasant and comfortably cold (scale with 5 steps) and slightly warm, pleasant-neutral, slightly cold (scale with 7 steps) by the surveyed students.

The frequency of students, who perceived thermal sensation as pleasant, decreases from scale with 3 steps to scale with 7 steps (from 57.79 to $37.66 \%$ ) during the winter, and it decreases from 70.75 to $49.66 \%$ (scale with 3 steps to scale with 7 steps, respectively) during the spring. An explanation is that a part of the votes for pleasant went to comfortably warm or comfortably cold and to slightly warm or slightly cold (Table 3 ).

The perceived thermal sensation as discomfort, assessed by scales with 3, 5 and 7 steps, was greater for cold than warm $(27.27 \% / 14.94 \%$-scale with 3 steps; $11.69 \% / 3.9 \%$ - scale with 5 steps and $13.64 \%$ / $11.69 \%$ - scale with 7 steps) during the winter, and it was greater for warm than cold $(28.57 \% / 0.68 \%$ - scale with 3 steps; $8.85 \% / 0.68 \%$-scale with 5 steps and $19.73 \% / 0 \%$ - scale with 7 steps) during the spring (Table 3).

\section{The perception of comfortable thermal sensation throughout the 4 days of the survey}

A tendency of the students to perceive the comfortably cold thermal sensation (slightly cold and comfortably cold) more frequently than comfortably warm thermal sensation (slightly warm and comfortably warm) throughout the 4 days of the survey during the winter, except Monday, was demonstrated in this study (Table 4). During the spring the students perceived comfortably warm more frequently than comfortably cold thermal sensation throughout all the days of the survey (Table 4).

\section{The perception of thermal sensation as discomfort throughout the 4 days of the survey}

The thermal sensation perceived as warm discomfort-1 and 2 (scale with 7 steps on $\mathrm{M} 30.43 \%$, Tu $0 \%$, W 16.13\%, Th 15\%-winter; M 44.45\%, Tu $4.08 \%$, W $17.95 \%$, Th 25\%-spring)-was more frequently affirmed by students than cold discomfort-7 and 6 (scale with 7 steps on M 4.37\%, Tu 25\%, W $3.22 \%$, Th $10 \%$-winter; M 0\%, Tu 0\%, W 0\%, Th $0 \%$-spring)-throughout the four successive days of the survey during both seasons, except Tuesday, during the winter. On Tuesday, the thermal sensation was more frequently perceived as cold discomfort (very cold-7 and cold-6) than warm discomfort (very warm-1 and warm-2), during the winter.

\section{Perceived thermal sensation (scale with 7 steps) and} environmental factors (temperature, relative humidity, wind velocity and NET)

During the winter a similar evolution of the perceived thermal sensation and of the NET was demonstrated (Table 5). NET integrated the three environmental factors, acting together on the human body. Kruskal-Wallis $\mathrm{H}$ test indicated a slightly significant difference (chi square $\chi^{2}=12.5$, Sig. 0.012)

Table 2 Microclimate factors and NET (median) throughout the 4-day survey during the winter and spring

\begin{tabular}{|c|c|c|c|c|c|c|c|c|}
\hline \multirow[t]{2}{*}{ Days of the week } & \multicolumn{4}{|l|}{ Winter } & \multicolumn{4}{|l|}{ Spring } \\
\hline & $\operatorname{Air} \mathrm{T}\left({ }^{\circ} \mathrm{C}\right)$ & Rel. Hu (\%) & Wind vel. $(\mathrm{m} / \mathrm{s})$ & NET ${ }^{\circ} \mathrm{ET}$ & Air $\mathrm{T}\left({ }^{\circ} \mathrm{C}\right)$ & Rel. Hu (\%) & Wind vel. $(\mathrm{m} / \mathrm{s})$ & NET ${ }^{\circ}$ ET \\
\hline Monday & 20.7 & 37 & 0.21 & 18.84 & 21.9 & 51 & 0.26 & 20.17 \\
\hline Tuesday & 20.1 & 34 & 0.17 & 18.45 & 22.1 & 45 & 0.19 & 20,27 \\
\hline Wednesday & 19.2 & 41 & 0.09 & 18.40 & 22.5 & 60 & 0.13 & 21.49 \\
\hline Thursday & 19.8 & 42 & 0.17 & 18.55 & 24.5 & 61 & 0.33 & 22.54 \\
\hline Mean & 19.95 & 38.5 & 0.16 & 18.56 & 22.75 & 54.25 & 0.23 & 21.11 \\
\hline
\end{tabular}

Air $T$ air temperature, Rel. Hu relative humidity, Wind vel. wind velocity, NET normal effective temperature 
Table 3 Thermal sensation perceived (3-, 5- and 7-step scales) by students during the winter and spring

\begin{tabular}{|c|c|c|c|c|c|c|c|c|c|c|c|c|c|c|c|c|c|c|}
\hline \multirow{3}{*}{ Scale } & \multicolumn{18}{|c|}{ Frequency of students (number and percent) } \\
\hline & \multicolumn{9}{|c|}{ Winter } & \multicolumn{9}{|c|}{ Spring } \\
\hline & \multicolumn{3}{|c|}{3 steps } & \multicolumn{3}{|c|}{5 steps } & \multicolumn{3}{|c|}{7 steps } & \multicolumn{3}{|c|}{3 steps } & \multicolumn{3}{|c|}{5 steps } & \multicolumn{3}{|c|}{7 steps } \\
\hline & w & 23 & $14.94 \%$ & uw & 6 & $3.90 \%$ & vW & 2 & $1.30 \%$ & w & 42 & $28.57 \%$ & uw & 13 & $8.85 \%$ & vW & 3 & $2.04 \%$ \\
\hline & & & & & & & w & 16 & $10.39 \%$ & & & & & & & w & 26 & $17.69 \%$ \\
\hline & & & & $\mathrm{cW}$ & 26 & $16.88 \%$ & sw & 16 & $10.39 \%$ & & & & $c W$ & 47 & $31.97 \%$ & sw & 34 & $23.13 \%$ \\
\hline & $\mathrm{p}$ & 89 & $57.79 \%$ & $p$ & 63 & $40.91 \%$ & $p$ & 58 & $37.66 \%$ & $p$ & 104 & $70.75 \%$ & $p$ & 77 & $52.38 \%$ & $p$ & 73 & $49.66 \%$ \\
\hline & & & & $\mathrm{CC}$ & 41 & $26.62 \%$ & SC & 41 & $26.62 \%$ & & & & $c c$ & 9 & $6.12 \%$ & SC & 11 & $7.48 \%$ \\
\hline & & & & & & & c & 18 & $11.69 \%$ & & & & & & & c & $\mathrm{nv}$ & nv \\
\hline & $c$ & 42 & $27.27 \%$ & uc & 18 & $11.69 \%$ & ve & 3 & $1.95 \%$ & $c$ & 1 & $0.68 \%$ & uc & 1 & $0.68 \%$ & ve & $\mathrm{nv}$ & nv \\
\hline Total & & 154 & $100 \%$ & & 154 & $100 \%$ & & 154 & $100 \%$ & & 147 & $100 \%$ & & 147 & $100 \%$ & & 147 & $100 \%$ \\
\hline
\end{tabular}

$w$ warm, $p$ pleasant, $c$ cold, uw uncomfortably warm, $c w$ comfortably warm, $p$ pleasant, $c c$ comfortably cold, uc uncomfortably cold, $v w$ very warm, $w$ warm, sw slightly warm, pleasant, sc slightly cold, vc cold, $n v$ no values

among the 5 groups from 7 (2-warm, 3-slightly warm, 4-pleasant, 5-slightly cold, 6-cold and with more than 5 students) with perceived thermal sensations for air relative humidity values registered during the winter. Mann-Whitney $U$ test with Bonferroni correction indicated a statistically significant difference between groups with perceived thermal sensations as 2-warm and 6-cold (MannWhitney $=52, Z=-3.31$, Sig. 0.005) for registered air relative humidity values. No significant differences for air temperature and wind velocity registered values were found among the same 5 groups, during the winter.

During the spring the very cold and cold thermal sensations were not perceived at all. The evolution of NET was similar with the pleasant, slightly warm and warm perceived thermal sensation evolution. Exceptions were registered for slightly cold and very warm
(Table 5). No differences (Kruskal-Wallis $H$ test without statistical significance) were found among the 4 groups from 7 (2-warm, 3-slightly warm, 4-pleasant and 5-slightly cold and with more than 5 students) with perceived thermal sensations for registered values of air temperature, air relative humidity and wind velocity, during the spring.

\section{Predictors of thermal sensation in the amphitheatre}

Nationality (country) and air relative humidity were found as predictors for the pleasant thermal sensation (alternative 2) compared with warm thermal sensation (reference category 1), perceived (scale with 3 steps) by students in the amphitheatre, during the winter and analysed through multinomial logistic regression. Gender and air relative humidity resulted as predictors for the cold thermal sensation (alternative 3) compared with warm thermal sensation (reference

Table 4 Comfortable thermal sensation perceived by students (\%) throughout 4 days during the winter and spring

\begin{tabular}{|c|c|c|c|c|c|c|c|c|c|}
\hline \multirow[b]{3}{*}{ Day of the week } & \multicolumn{3}{|c|}{ Steps of the 3 scales } & \multicolumn{6}{|c|}{ Frequency of students } \\
\hline & & & & \multicolumn{3}{|l|}{ Winter } & \multicolumn{3}{|l|}{ Spring } \\
\hline & & & & 3 steps & 5 steps & 7 steps & 3 steps & 5 steps & 7 steps \\
\hline & & $c W$ & sw & & $34.78 \%$ & $17.39 \%$ & & $48.14 \%$ & $22.22 \%$ \\
\hline \multirow[t]{3}{*}{ Monday } & $\mathrm{p}$ & $p$ & $p$ & $60.87 \%$ & $43.48 \%$ & $43.47 \%$ & $44.44 \%$ & $25.93 \%$ & $33.33 \%$ \\
\hline & & $\mathrm{CC}$ & sC & & $4.34 \%$ & $4.34 \%$ & & $0 \%$ & $0 \%$ \\
\hline & & $c W$ & sw & & $3.33 \%$ & $5.00 \%$ & & $20.41 \%$ & $20.41 \%$ \\
\hline \multirow[t]{3}{*}{ Tuesday } & $p$ & $\mathrm{p}$ & $p$ & $56.67 \%$ & $38.33 \%$ & $38.33 \%$ & $87.76 \%$ & $69.39 \%$ & $69.39 \%$ \\
\hline & & $\mathrm{CC}$ & SC & & $33.33 \%$ & $31.67 \%$ & & $6.12 \%$ & $6.12 \%$ \\
\hline & & $\mathrm{cW}$ & sw & & $22.58 \%$ & $9.68 \%$ & & $38.46 \%$ & $30.77 \%$ \\
\hline \multirow[t]{3}{*}{ Wednesday } & $\mathrm{p}$ & $p$ & $p$ & $64.52 \%$ & $48.38 \%$ & $45,16 \%$ & $79.49 \%$ & $48.72 \%$ & $35.90 \%$ \\
\hline & & $\mathrm{CC}$ & SC & & $22.58 \%$ & $25.81 \%$ & & $10.26 \%$ & $15.38 \%$ \\
\hline & & $c W$ & sw & & $22.50 \%$ & $15.00 \%$ & & $28.13 \%$ & $18.75 \%$ \\
\hline \multirow[t]{2}{*}{ Thursday } & $p$ & $p$ & $p$ & $52.50 \%$ & $37.50 \%$ & $27.50 \%$ & $56.25 \%$ & $53.12 \%$ & $50.00 \%$ \\
\hline & & $\mathrm{CC}$ & SC & & $32.50 \%$ & $32.50 \%$ & & $6.25 \%$ & $6.25 \%$ \\
\hline
\end{tabular}


Table 5 Perceived thermal sensation (scale with 7 steps) and environmental factors during the winter and spring

\begin{tabular}{|c|c|c|c|c|c|c|c|c|}
\hline \multicolumn{5}{|l|}{ Winter } & \multicolumn{4}{|l|}{ Spring } \\
\hline & Air T $\left({ }^{\circ} \mathrm{C}\right)$ & Rel. Hu (\%) & Wind vel. $(\mathrm{m} / \mathrm{s})$ & $\overline{N E T}{ }^{\circ} \mathrm{ET}$ & Air T $\left({ }^{\circ} \mathrm{C}\right)$ & Rel. Hu (\%) & Wind vel. $(\mathrm{m} / \mathrm{s})$ & NET ${ }^{\circ} E T$ \\
\hline $\bar{N}$ & 3 & 3 & 3 & & 0 & 0 & 0 & \\
\hline M Very cold & 20.00 & 36.66 & 0.17 & 18.48 & nv & nv & nv & $\mathrm{nv}$ \\
\hline SD & 0.17 & 4.61 & 0.00 & & & & & \\
\hline $\mathrm{N}$ & 18 & 18 & 18 & & 0 & 0 & 0 & \\
\hline M Cold & 20.03 & 35.88 & 0.16 & 18.51 & $\mathrm{nv}$ & $n v$ & nv & nv \\
\hline SD & 0.28 & 3.30 & 0.02 & & & & & \\
\hline $\mathrm{N}$ & 41 & 41 & 41 & & 11 & 11 & 11 & \\
\hline M Slightly cold & 19.84 & 37.97 & 0.15 & 18.51 & 22.75 & 56.09 & 0.18 & 21.32 \\
\hline SD & 0.36 & 3.82 & 0.03 & & 0.88 & 7.13 & 0.07 & \\
\hline$N$ & 58 & 58 & 58 & & 73 & 73 & 73 & \\
\hline M Pleasant & 19.92 & 37.72 & 0.15 & 18.55 & 22.67 & 52.12 & 0.21 & 20.97 \\
\hline SD & 0.49 & 3.44 & 0.041 & & 0.98 & 7.32 & 0.06 & \\
\hline $\mathrm{N}$ & 16 & 16 & 16 & & 34 & 34 & 34 & \\
\hline M Slightly warm & 19.96 & 39.06 & 0.16 & 18.58 & 22.62 & 54.17 & 0.20 & 21.05 \\
\hline SD & 0.52 & 3.23 & 0.040 & & 0.9 & 6.9 & 0.07 & \\
\hline$N$ & 16 & 16 & 16 & & 26 & 26 & 26 & \\
\hline M Warm & 19.95 & 39.81 & 0.16 & 18.58 & 22.77 & 55.65 & 0.23 & 21.17 \\
\hline SD & 0.64 & 2.28 & 0.051 & & 1.09 & 5.57 & 0.07 & \\
\hline$N$ & 2 & 2 & 2 & & 3 & 3 & 3 & \\
\hline M Very warm & 20.25 & 39.50 & 0.19 & 18.7 & 22.76 & 54.33 & 0.28 & 20.94 \\
\hline SD & 0.63 & 3.53 & 0.028 & & 1.50 & 5.77 & 0.04 & \\
\hline
\end{tabular}

Air $T$ air temperature, Rel. Hu relative humidity, Wind vel. wind velocity, $N$ number of students, $M$ mean values, $S D$ standard deviation, $n v$ no values

category 1), perceived during the winter, assessed through the scale with 3 steps and analysed through multinomial logistic regression.

Nationality (country) and wind velocity were demonstrated as predictors for the warm thermal sensation perceived by students during the spring, on the scale with 3 steps (warm, no warm-pleasant, cold being excluded due to insignificant number of cases -1 case), and analysed through binary logistic regression.

\section{Nationality}

Nationality was found as a significant personal predictor (-2loglikelihood change in reduced model or chi square $=42.12$, Sig. 0.000) (Table 6) of the perceived thermal sensation (scale with 3 steps) by Romanian, Israeli, German, Italian, Greek, Syrian, Indian and other nationality students, during the winter. Therefore, Romanian students $(B=17.34$, SE $=0.62$, Sig. 0.000, $\operatorname{Exp}(B)=3.426 \mathrm{E} 7$ ) (Table 7) were situated in the alternative 2 category (pleasant) more frequently than in the reference 1 category (warm) of the perceived thermal sensation. Opposite and with less signification, Israeli students $(B=-1.74, S E=0.86$, Sig. 0.04, $\operatorname{Exp}(B)=0.175)($ Table 7$)$ were situated more frequently in the reference 1 category (warm) than in the alternative 2 (pleasant) of the perceived thermal sensation. The used model was $57.8 \%$ accurate. Romanian students perceived the microclimate as being colder $(48.1 \%)$ than warm $(0 \%)$, different from the other nationalities who perceived microclimate as being warmer than cold: Israeli $37 \%$ warm and $11.1 \%$ cold, German $22.1 \%$ warm and $16.7 \%$ cold, and Italian 20\% warm and $15 \%$ cold, during the winter. Statistically significant differences of the perceived thermal sensation were found between Romanian and Israeli (chi square $X^{2}=26.89, \quad$ Sig. 0.000 -scale with 3 steps); Romanian and Italian $\left(\chi^{2}=15.34\right.$, Sig. 0.000 -scale with 3 steps); Romanian and German $\left(\chi^{2}=15.53\right.$, Sig. 0.000-3 steps scale) students during the winter. Although no significant differences were found between Romanian and other nationalities during the spring, nationality resulted as a predictor (change in -2 loglikelihood $=20.85$, Sig. 0.004) (Table 8 ) of the perceived thermal sensation especially for Romanian students $(B=-1.71, S E=0.66$, Sig. $0.01, \operatorname{Exp}(B)=0.18)($ Table 9$)$. The used model was $71.9 \%$ accurate. Here it is demonstrated through binary logistic regression the tendency of the Romanian students to perceive more frequently no-warm (pleasant) than warm thermal sensation, during the spring. 
Table 6 Multinomial logistic regression models of predictors of the perceived thermal sensation (3-step scale, winter)

\begin{tabular}{|c|c|c|c|c|}
\hline \multirow[t]{2}{*}{ Effect } & \multirow{2}{*}{$\begin{array}{l}\text { Model fitting criteria } \\
\text {-2loglikelihood of reduced model }\end{array}$} & \multicolumn{3}{|c|}{ Likelihood ratio tests } \\
\hline & & Chi square & $d f$ & Sig. $(p$ value \\
\hline Intercept & $36.933^{\mathrm{a}}$ & .000 & 0 & \\
\hline Country & 79.055 & 42.121 & 14 & .000 \\
\hline Intercept & $38.986^{\mathrm{a}}$ & .000 & 0 & \\
\hline Gender & 51.719 & 12.733 & 2 & .002 \\
\hline B3-sensitivity to cold & 52.895 & 13.909 & 6 & .031 \\
\hline Intercept & $49.015^{\mathrm{a}}$ & 3.509 & 2 & .173 \\
\hline Humidity indoor winter & 56.160 & 10.655 & 2 & .005 \\
\hline NET_normal effective temperature & 47.197 & 1.692 & 2 & .429 \\
\hline
\end{tabular}

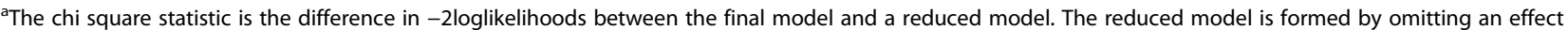
from the final model. The null hypothesis is that all parameters of that effect are 0

\section{Relative humidity}

Relative humidity resulted as an environmental predictor (-2loglikelihood change in reduced model or chi square $=10.655$, Sig. 0.005) (Table 6) of the perceived thermal sensation for scale with 3 steps, during the winter. Humidity decrease determined a number decrease of the students who perceived thermal sensation as cold (alternative 3: $\mathrm{B}=-0.28$, $\mathrm{SE}=0.09$, Sig. 0.002, $\operatorname{Exp}(\mathrm{B})=0.75)$ and pleasant (alternative 2: $\mathrm{B}=-0.21, \mathrm{SE}=0.08$, Sig. 0.012, $\operatorname{Exp}(\mathrm{B})$ $=0.81$ ) (Table 7) in comparison with thermal sensation perceived as warm (reference 1). This result registered a weak statistical significance and it was revealed by multinomial logistic regression. The used model was $57.8 \%$ accurate. A statistically significant difference of relative humidity resulted between places of students who perceived thermal sensation as being warm and cold $\left(\chi^{2}=28.39\right.$, Sig. 0.000-3step scale), during the winter.

Table 7 Multinomial logistic regression parameters estimates of predictors of the perceived thermal sensation (3-step scale, winter)

\begin{tabular}{llllll}
\hline Warm $=1$, Pleasant $=2$, Cold $=3^{\mathrm{a}}$ & $\mathrm{B}$ & SE & Sig. & Exp(B) \\
\hline 2 & Intercept & 2.079 & .750 & .006 & \\
& [Country = 1] Romania & 17.349 & .622 & .000 & $3.426 \mathrm{E7}$ \\
& [Country = 2] Israel & -1.743 & .857 & .042 & .175 \\
$3 \quad$ Intercept & 1.219 & .845 & .149 & \\
& [Gender = 0] Male & -2.064 & .644 & .001 & .127 \\
& [B3=2] very sensitive to cold & 1.547 & .956 & .106 & 4.699 \\
$2 \quad$ Intercept & 9.938 & 5.344 & .063 & \\
& Humidity indoor winter & -.211 & .084 & .012 & .810 \\
& NET & -.018 & .191 & .924 & .982 \\
Intercept & 6.715 & 6.615 & .310 & \\
Humidity indoor winter & -.280 & .092 & .002 & .756 \\
NET & .260 & .260 & .317 & 1.297 \\
\hline
\end{tabular}

$B$ the logistic coefficient, SE standard error, Sig. $p$ value, Exp(B)-odd ratio ${ }^{a}$ The reference category-1;2,3-alternative categories

\section{Wind velocity}

When a binary logistic regression was applied to model including wind velocity $(\mathrm{wv}, \mathrm{m} / \mathrm{s})$, it was found to be an environmental predictor (change in -2loglikelihood $=11.96$, Sig. 0.001) (Table 8) of the thermal sensation perceived by students for scale with 3 steps (warm, pleasant-no warm, cold-excluded) during the spring. An interesting result was that an increase of the wind velocity into the amphitheatre was associated with an increase in of the frequency of students who perceived the warm thermal sensation $(B=8.68, S E=2.60$, Sig. $0.001, \operatorname{Exp}(0.05 * \mathrm{~B})=2.38$ ) (Table 9) in comparison with students who perceived no-warm (pleasant) thermal sensation. The used model was $71.4 \%$ accurate. The natural ventilation of the amphitheatre and the warm air movement ("Föhn" or "cosava") in the Banat (the region where Timisoara is situated) during the spring could be a possible explanation.

\section{Gender}

Gender was demonstrated as a personal predictor (-2loglikelihood change in reduced model or chi square $=12.73$, Sig. 0.002) (Table 6) of the perceived thermal sensation for the scale with 3 steps, during the winter. Male students perceived thermal sensation less frequently as cold (alternative $3: \mathrm{B}=-2.06, \mathrm{SE}=0.64$, Sig. $0.001, \operatorname{Exp}(B)=0.127$ ) (Table 7) compared with their perceived thermal sensation as warm (reference category 1 ). The used model was $62.3 \%$ accurate. This result was demonstrated through multinomial logistic regression.

Table 8 Binary logistic models for predictors of warm thermal sensation perceived by students during the spring

\begin{tabular}{|c|c|c|c|c|c|}
\hline \multicolumn{2}{|c|}{ Variable } & \multirow{2}{*}{$\begin{array}{l}\text { Model } \\
\text { loglikelihood } \\
-87.387\end{array}$} & \multirow{2}{*}{$\begin{array}{l}\text { Change in } \\
\text {-2loglikelihood } \\
20.853\end{array}$} & \multirow{2}{*}{$\begin{array}{l}d f \\
7\end{array}$} & \multirow{2}{*}{$\begin{array}{l}\begin{array}{l}\text { Sig. of the } \\
\text { change }\end{array} \\
.004\end{array}$} \\
\hline Step 1 & Country & & & & \\
\hline Step 2 & $\begin{array}{l}\text { Wind } \\
\text { velocity spring }\end{array}$ & -88.032 & 11.960 & 1 & .001 \\
\hline
\end{tabular}

NET removed 
Table 9 Binary logistic regression variables for predictors of the warm perceived thermal sensation during the spring

\begin{tabular}{llllll}
\hline & & B & S.E. & Sig. & Exp(B) \\
\hline Step 1 & Country & & & .086 & \\
& Country(1) Romania & -1.715 & .666 & .010 & .180 \\
& Constant & -.636 & .412 & .123 & .529 \\
Step 1 & & & & & Exp(0.05*B) \\
& & & & .601 & 2.380 \\
& Wind velocity spring & 8.681 & 2.606 & .001 \\
& Constant & -2.885 & .643 & .000 & .003 \\
\hline
\end{tabular}

NET removed

$B$ the logistic coefficient, SE. standard error, Sig. $p$ value, $\operatorname{Exp}\left(0.05^{*} B\right)$-odd ratio for $0.05 \mathrm{~m} / \mathrm{s}$ variation

At the same exposure to microclimate, male students perceived the microclimate as warmer $(22.1 \%)$ than cold (13.2\%) and female students perceived the microclimate as being colder (38.4\%) than warm (9.3\%). A statistically significant difference of the perceived thermal sensation (warm, pleasant, cold) was found between genders during the winter (chi square $\chi^{2}=13.94$, Sig. 0.001-scale with 3 steps) and no statistically significant difference was found between genders during the spring.

A limit of the performed study is the prediction level between 0.57 and 0.72 (less accurate prediction) of the used models.

\section{Discussion}

The observational inquiry performed on medical students in an historic building (built 1945) with the investigation of the perceived thermal sensation and of the predictors that can affect it is similar to other epidemiological inquiries used as evaluation criteria of occupational microclimate regulation requirements [8]. The advantage is the great number of subjects surveyed in their natural learning situation, and the limitation is that they are observational. The observed associations can be only suggested and need further confirmation.

Research on thermal sensation (microclimate) perceived by learners in educational units was done in Italy [9] and in Greece [10] where the quantification of bio meteorological conditions in university halls was performed through Fanger's indexes and PET (physiological equivalent temperature) calculation. In another study the results demonstrated that human thermal load represents better the mixed sensation of the human thermal experience [11]. Thermal sensation indexes underestimated the perceived thermal sensation, and what proved more predictive was head load, though there was also a tendency to overestimate the thermal sensation of the subjects [12].

The powerful correlations between the 3 scales (with 3,5 and 7 steps) of the perceived thermal sensation and the calculated NET (corroborated with the perceived thermal sensation-scale with 7 steps) offered consistency of the obtained results.

The comfortable thermal sensation as it was perceived by students throughout the 4 days of the survey showed that students recorded themselves as more frequently comfortably cold than comfortably warm throughout the 4 days of the survey during the winter, except Monday, and more frequently comfortably warm than comfortably cold during the spring. In a study in China, seasonal acclimatization was confirmed, but it was found to have no significant impact on human thermal sensation or comfort [13]. An impact of seasons (winter and spring) on comfortable thermal sensation perceived by students resulted in the conducted study.

The thermal sensation of discomfort indicated the warm discomfort as being more frequently perceived than the cold discomfort throughout the four investigated days, during the winter and spring, except Tuesday, during the winter. Another study indicated the warm thermal sensation perceived as discomfort as being associated with physiological responses to warmth, which caused negative effects on health and performance of the investigated subjects [14].

In the performed study, certain personal factors (nationality and gender) and environmental factors (humidity) were demonstrated to be related to perceived thermal sensation during the winter, and the personal (nationality) and environmental factors (wind velocity) were found as related to perceived thermal sensation, during the spring.

In this study the perceived thermal sensation of students from 7 countries was also analysed: Romanian students coming from the area of study and the other nationalities coming from other geographic areas (The Middle East, Northern Europe and Southern Europe, and Asia), and even different climate areas (temperate, tropical and subtropical). Nationality was found as a predictor with statistical significance. Romanian students perceived more frequently pleasant than warm thermal sensation during both seasons (winter and spring). In China, climatic acclimatization was confirmed, but no significant impact on human thermal sensation was found [13]. Students who came from other countries to study in Romania perceived more frequently the warm thermal sensation than cold. A clear difference of thermal sensation perception between local students and newcomers was demonstrated in the performed study. In another study a questionnaire survey showed differences of thermal comfort of the subjects who were users of the beach from different areas (beach or urban) [15].

Humidity was found as a predictor of the perceived thermal sensation during the winter. A decrease of relative humidity reduces the students' thermal sensation perception for cold and pleasant in comparison with the 
perception for warm. Therefore, dry air is perceived by students more frequently as warm than cold or pleasant in the performed study, during the winter. Still, this result has a weak statistical significance. A study performed in China indicated the perception of air as dryer when using floor heating systems than when using radiant heating systems, although relative humidity was higher [16]. A statistically significant difference was found between humidity values measured at each place for students who perceived the cold thermal sensation and on the other hand students who perceived the warm thermal sensation. The relationship between humidity sensation and preferences showed in the other study that the effect of humidity on thermal comfort should not be ignored at high and low temperatures [17]. In another study in China, a relation between thermal comfort and microclimate factors was found and rated by importance: sun radiation, pressure, temperature, relative humidity and wind speed [18]. Another study's results indicated the necessity to approach thermal comfort issues in a way that attends to problematic situations that are more perceptual than real [19].

In the study conducted, wind velocity of indoor air was demonstrated as a predictor of the thermal sensation perceived by students during the spring. An interesting result of the performed study was that an increase of the wind velocity into the amphitheatre was associated with an increase of in frequency of students who perceived the warm thermal sensation compared with no-warm (pleasant) thermal sensation. In another study wind speed was demonstrated as a climate factor that improves thermal comfort through its variation [20]. Many field surveys have shown that naturally ventilated buildings are favourable to human thermal comfort, and wind velocity represents a characteristic of natural wind. The dynamic characteristics of natural wind correlate with thermal comfort [21].

Gender was demonstrated in the study as being a predictor of the thermal sensation perceived by students during the winter season. A statistically significant difference was found between male and female students regarding perceived thermal sensation. In this study the result was that male students perceive thermal sensation less frequently as being cold than warm. These results differ from another study from China in which no difference between genders was found in perceiving thermal sensation [18]. Another study performed in Greece, surveying a Mediterranean area, reported that females were more likely to report heat-related symptoms than males [3]. The sex difference for affective but not intensive ratings of innocuous temperatures revealed sex differences in thermal perception in other research [22].

No relation was found in the performed study between different levels of sensitivity of subjects to cold and the perceived thermal sensation during the winter. In a research study the cold thermal sensitivity was more homogenous for young participants than older ones [23].

No relations were found between perceived thermal sensation and clothing, BMI and indoor air temperature, during both seasons in the conducted study. In research literature the permeability of clothing decreased local microclimate temperature and relative humidity [24], or indirect relation body fat-exposure to microclimate factors and thermal discomfort resulted $[25,26]$.

Effects of the perceived comfortable thermal sensation (attention concentration, feeling well, physically relaxed) affirmed by students were not confirmed in this study, although in research literature a change of behaviour resulted on animals relating to their thermoregulation and climatic tolerances [27].

\section{Conclusions}

Certain personal and environmental factors are suggested as predictors for thermal sensation as it is perceived by a population of students in a classic study setting, naturally ventilated. Nationality and gender as personal factors were found in the performed study as predictors for the perceived thermal sensation, during the winter. Air relative humidity during the winter and wind velocity during the spring, were discovered as environmental factor predictors for the perceived thermal sensation. The prediction levels for these demonstrated factors were different; the highest predictors were nationality, wind velocity and relative humidity. Prediction was different depending on season: nationality, relative humidity and gender were predictive during the winter, and wind velocity and nationality were predictive during the spring.

Throughout the days of the survey, comfortable thermal sensation was perceived more frequently as comfortably cold than comfortably warm during the winter, except Monday, and thermal sensation of discomfort was perceived more frequently as warm discomfort than cold discomfort during both seasons, except Tuesday during the winter. Calculated NET corroborated with the perceived thermal sensation (scale with 7 steps) during both seasons, with certain exceptions during the spring.

\section{Abbreviations}

ASV: Actual sensation vote; M: Monday; NET: Normal effective temperature; NV: Naturally ventilated; PET: Physiological equivalent temperature; PMV: Predicted mean vote; Th: Thursday; Tu: Tuesday; UTCI: Universal Thermal Climate Index; W: Wednesday

\section{Acknowledgements}

The author wishes to offer her recognition for the contribution of Jean-Christophe Abel Ba Sidi, MD student in building the data base for this study and for the meteorological data contribution of Meteorologist Silvia Barbu, Director of the Regional Meteorological Center Banat-Crisana. 


\section{Funding}

There was no institutional funding for this study.

\section{Availability of data and materials}

The datasets used and/or analysed during the current study available from the corresponding author on reasonable request.

\section{Authors' contributions}

CP initiated and designed the research plan, applied the methods, analysed and interpreted data of this research study. She prepared this manuscript entirely.

\section{Competing interests}

The author declares that she has no competing interests.

\section{Consent for publication}

Not applicable.

\section{Ethics approval and consent to participate}

All procedures performed in this study involving human participants were in accordance with the ethical standards of the institutional and/or national research committee and with the 1964 Helsinki declaration and its later amendments or comparable ethical standards.

The informed consent of each student to participate in the study was asked for and obtained.

\section{Publisher's Note}

Springer Nature remains neutral with regard to jurisdictional claims in published maps and institutional affiliations.

Received: 18 January 2017 Accepted: 4 June 2017

Published online: 14 June 2017

\section{References}

1. Wang L, Yin H, Di Y, Liu Y, Liu J. Human local and total heat loses in different temperature. Physiol Behav. 2016;157:270-6.

2. Hoppe $P$. The physiological equivalent temperature - a universal index for the biometeorological assessment of the thermal environment. Int J Biometeorol. 1999;43(2):71-5

3. Dahlan ND, Gital YY. Thermal sensation and comfort investigations in transient conditions in tropical office. Appl Ergon. 2016;54:169-76.

4. Pantavou KG, Lykoudis SP, Nikolopoulos GK. Milder form of heat related symptoms and thermal sensation: a study in a Mediterranean climate. Int $J$ Biometeorol. 2016;60(6):917-29.

5. Blazejczyk K, Epstein Y, Jendritzky G, Staiger H, Tinz B. Comparison of UTC to selected thermal indices. Int J Biometeorol. 2012;56(3):515-35.

6. De Deara RJ, Bragerb GS. Thermal comfort in naturally ventilated buildings: revisions to ASHRAE Standard 55. Energ Buildings. 2002;34:549-61.

7. Humphreys MA, Hancock M. Do people like to feel "neutral"?: Exploring the variation of the desired thermal sensation on the ASHRAE scale. Energ Buildings. 2007;39(7):867-74.

8. Afanasèva RF, Bessonova NA, Burmistrova OV, Burmistrov VM, Losik TK Occupational microclimate. Results and prospects of research. Med Tr Prom Ekol. 2013:(6):30-35. PubMed 23986949.

9. De Giuli V, Zecchin R, Corain L, Salmaso L. Measured and perceived environmental comfort: field monitoring in an Italian school. Appl Ergon. 2014;45(4):1035-47.

10. Nastos PT, Polychroni ID. Modelling and in situ measurements of biometeorological conditions in microenvironments within the Athens University Campus, Greece. Int J Biometeorol. 2016:60(10). doi:10.1007/ s00484-016-1137-8

11. Shimazaki Y, Yoshida A, Yamamoto T. Thermal responses and perceptions under distinct ambient temperature and wind conditions. J Therm Biol. 2015;49-50:1-8.

12. Pantavou K, Chatzi E, Theoharatos G. Case study of skin temperature and thermal perception in a hot outdoor environment. Int J Biometeorol. 2014; 58(6):1163-73

13. Zhang Y, Chen H, Wang J, Meng Q. Thermal comfort of people in the hot and humid area of China - impacts of season, climate and thermal history. Indoor Air. 2016;26(5):820-30. doi:10.1111/ina.12256.
14. Lan L, Wargocki P, Wyon DP, Lian Z. Effects of thermal discomfort in an office on perceived air quality, SBS symptoms, physiological responses, and human performance. Indoor Air. 2011;21(5):376-90. doi:10.1111/j.1600-0668. 2011.00714x.

15. Rutty M, Scott D. Bioclimatic comfort and the thermal perceptions and preferences of beach tourists. Int J Biometeorol. 2015:59(1):37-45.

16. Wang Z, Ning H, Ji Y, Hou J, He Y. Human thermal physiological and psychological responses under different heating environments. J Therm Biol. 2015:52:177-86.

17. Li B, Tan M, Liu H, Ma X, Zhang W. Perception and preference of thermal environment in free-running buildings in China. Indoor Built Environ. 2010; 19(4):405-12.

18. Yin J, Zheng Y, Wu R, Tan J, Ye D, Wang W. An analysis of influential factors on outdoor thermal comfort in summer. Int J Biometeorol. 2012;56(5):941-8.

19. Lenzholzer S. Engrained experience - a comparison of microclimate perception schemata and microclimate measurements in Dutch urban squares. Int J Biometeorol. 2010;54(2):141-50.

20. Rodrigues Algeciras JA, Coch H, De la Paz Perez G, Chaos Years M, Matzarakis A. Human thermal comfort conditions and urban planning in hot-humid climates - The case of Cuba. Int J Biometeorol. 2015;60(8):115164. doi:10.1007/s00484-015-1109-4.

21. Kang KN, Song D, Schiavon S. Correlation in thermal comfort and natural wind. J Therm Biol. 2013;38(7):419-26

22. Sarlani E, Faroog N, Greenspan JD. Gender and laterality differences in thermo-sensation throughout the perceptible range. Pain. 2013;106(1-2):9-18.

23. Inoue Y, Gerrett N, Ichinose-Kuwahara T, Umino Y, Kiuchi S, Amano T, Ueda $H$, Havenith $G$, Kondo N. Sex differences in age related changes on peripheral warm and cold innocuous thermal sensitivity. Physiol Behav. 2016;164(Pt A):86-92.

24. Chen TH, Chen WP, Wang MJ. The effect of air permeability and water vapor permeability of cleanroom clothing on physiological responses and wear comfort. J Occup Environ Hyg. 2014;11(6):366-76.

25. Morinaka T, Wozniewicz M, Jeszka J, Bajerska J, Limtrakul P, Makonkawkeyoon L, Hirota N, Kumagai S, Sone Y. Comparison of seasonal variation in the fasting respiratory quotient of young Japanese, Polish and Thai women in relation to seasonal change in their percent body fat. J Physiol Antropol. 2012;31(1):10.

26. Langeveld M, Tan CY, Soeters M, Virtue S, Watson L, Murgatroyd P, Chaterjee VK, Vidal-Puiq T. Mild cold effects on hunger, food intake, satiety and skin temperature in humans. Endocr Connect. 2016;5(2):65-73. doi:10. 1530/EC-16-0004.

27. Moyer-Horner L, Mathewson PD, Jones GM, Kearney MR, Porter WP. Modelling behavioural thermoregulation in a climate change sentinel. Ecol Evol. 2015:24:5810-22

\section{Submit your next manuscript to BioMed Central and we will help you at every step:}

- We accept pre-submission inquiries

- Our selector tool helps you to find the most relevant journal

- We provide round the clock customer support

- Convenient online submission

- Thorough peer review

- Inclusion in PubMed and all major indexing services

- Maximum visibility for your research

Submit your manuscript at www.biomedcentral.com/submit
Biomed Central 